\title{
The New Generation of OR Enthusiasts: the AIROYoung Experiment
}

\author{
Lavinia Amorosi ${ }^{1}$ - Martina Fischetti ${ }^{2}$
}

Published online: 14 July 2020

(C) Springer Nature Switzerland AG 2020

\begin{abstract}
This special issue is dedicated to young researchers in operations research (OR) and to the newest topics of research in this field. To better understand the new generations of OR enthusiasts, what they are working on, and how they are going to feel part of this research community, the issue is dedicated to the 4th AIROYoung Workshop (Bolzano, 5-7 February 2020) and to the Italian AIROYoung chapter experience. AIROYoung is an example of a successful initiative that was born "from young researchers for young researchers": volunteering PhDs and young OR specialists put their time and energies to create a young community, offer resources, and foster the collaboration between universities and industries. The issue will contain both scientific papers on the newest research topics, and extra contents and interviews to picture the community behind AIROYoung, and why it is important for young OR researchers around the world to feel part of a community.
\end{abstract}

\section{AIROYoung: Our Story and Our Core Values}

AIROYoung Researchers Chapter is part of the Italian Operational Research Society (AIRO) and, despite its recent birth, it has managed to create a very large and increasingly active community. Back in 2016, a group of PhDs and PostDocs was sitting at a table, during the social dinner of the AIRO (Italian Association of Operations Research) annual conference. The group consisted mainly of Italian PhDs, part of them doing their $\mathrm{PhD}$ abroad. The conversation handed up in a discussion about different $\mathrm{PhD}$ systems in different institutions and parts of the world. What emerged was that some students had more opportunities than others (due to the difference in

Lavinia Amorosi

lavinia.amorosi@uniroma1.it

$\bowtie \quad$ Martina Fischetti

martina.fischetti@vattenfall.com

1 Department of Statistical Sciences, Sapienza University of Rome, Rome, Italy

2 Vattenfall BA Wind, Kobenhavn, Denmark 
funds from different research groups), in particular when it comes to conferences. We strongly believe that conferences are important for $\mathrm{PhD}$ students and early careers, as they give them a possibility to present their work, improve their presentation skills, get in contact with other PhDs, and maybe start collaborations. It is also very important for PhDs to feel part of a community, because they can face both practical and stress problems during their $\mathrm{PhD}$, and it is good to have people around in the same situation, with whom to share issues and look for feedbacks. A gap between universities and industries also emerged during the conversation.

The group took these thoughts home and noticed that, indeed, a young chapter is often missing in OR Associations, and in the specific, one was missing in the Italian one. Four of the people sitting at that table (Lavinia Amorosi, Veronica Dal Sasso, Martina Fischetti, and Alberto Santini) decided then to act on this and to pursue this idea of creating a community to support all $\mathrm{PhDs}$ students, independently from their own funds. This is why in February 2017 they organized the first AIROYoung workshop in Rome, an event free of charge and fully focused on PhDs. The aim of the workshop was to start creating this community and to offer a conference where everybody could join, independently from their university funds. Thanks to the support from AIRO and EURO, indeed, the first AIROYoung workshop was able to offer also grants for the people that had difficulties to cover the expenses to get to the conference. The workshop was a success, and the engagement showed that the initial intuition was right: many young OR enthusiasts (from Italy and from all over the world) were looking for such a community. The AIROYoung workshop, with free participation and grants, continued ever since and became an annual meeting for all young researchers (Fig. 1).

AIROYoung created and continuously maintains also a website (airoyoung.org) to keep the community active also outside of the workshops. People from all over the world can sign up to AIROYoung and to AIROYoung mailing list through the website, so to be up to date with the latest news in the community.

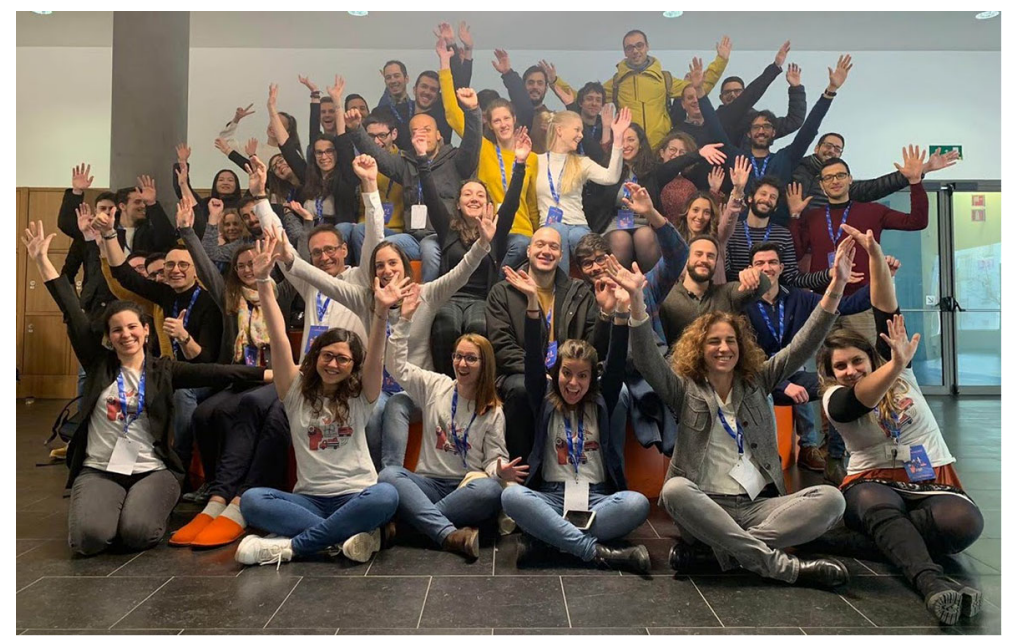

Fig. 1 AIROYoung is an inclusive community. Picture from the 4th AIROYoung workshop in Bozen (2020) 
The other main mission of AIROYoung is to foster collaboration between companies/universities and students, so as to offer help to the AIROYoungers searching for a job. The website contains two sections dedicated to opportunities and talents, where (respectively) companies/universities can post job opportunities in OR and students can share their CVs. Industrial sponsors are also very welcome at our workshops.

Given the enthusiasm from the young community, the AIROYoung chapter was further structured in 2018, with the election of two coordinators (Martina Fischetti and Lavinia Amorosi), one treasurer (Valentina Morandi), and two social media managers (Alice Raffaele and Serena Fugaro). Since 2017, AIROYoung never stopped organizing workshops for young researchers in OR all over Italy (Catanzaro, Rome, Bolzano) and creating numerous events for the international $\mathrm{PhD}$ community. The activities of AIROYoung and its passion for engaging new students to operations research have also been a model for other OR communities around the world. In particular, the original founders of AIROYoung also founded EUROYoung, which is our twin community at a European level.

\section{How to Create a New Community: Our Events and Our Experiences}

Since the first edition in 2017, the AIROYoung Workshop has become an annual international occasion for $\mathrm{PhD}$ students and young researchers to meet, exchange knowledge, and present novel research contributions in the field of operational research and decision and data science. The format of the event mainly provides for a location selected among Italian universities, as we are part of the Italian OR society, and no fees for participants. Indeed, the workshop has always been designed to include all kind of students, independently from their university fund. For this reason, some of the funds are also dedicated every year to offer grants (i.e., free accommodation) for some participants (in order to help even more who has reduced funds for traveling). This is possible both thanks to the support of AIRO and the search for sponsors to be engaged, especially among the local industrial realities. Over the years, new initiatives have been introduced. One example is the 1st AIROYoung $\mathrm{PhD}$ school which took place in Rome in 2019, attached annual workshop. Also, the school followed the AIROYoung value, offering lectures in OR, success stories from industries, tutorials, and network activities, with no fee for participants. Our focus was, of course, on the needs of $\mathrm{PhD}$ students. We realized that, during a $\mathrm{PhD}$, a student faces both theoretical challenges ("what method should I use? what is the status of the literature?") and practical challenges ("how do I code this idea? How do I manage the project?"). To help with both, we organized the PhD school so as to have both theoretical lessons taught by prominent international professors and practical tutorials (related to the use of different solvers or general coding tips), in a new format that we called "from young to young." PostDocs or PhDs at the end of their project were, indeed, sharing practical tips that they would have found useful to know during their first years. The event was accompanied by the workshop where instead the focus was on giving space to the PhDs to talk about their work and improve their communication skills. The two events were very successful with the participation of 60 students from many European countries and from Canada (Fig. 2). 


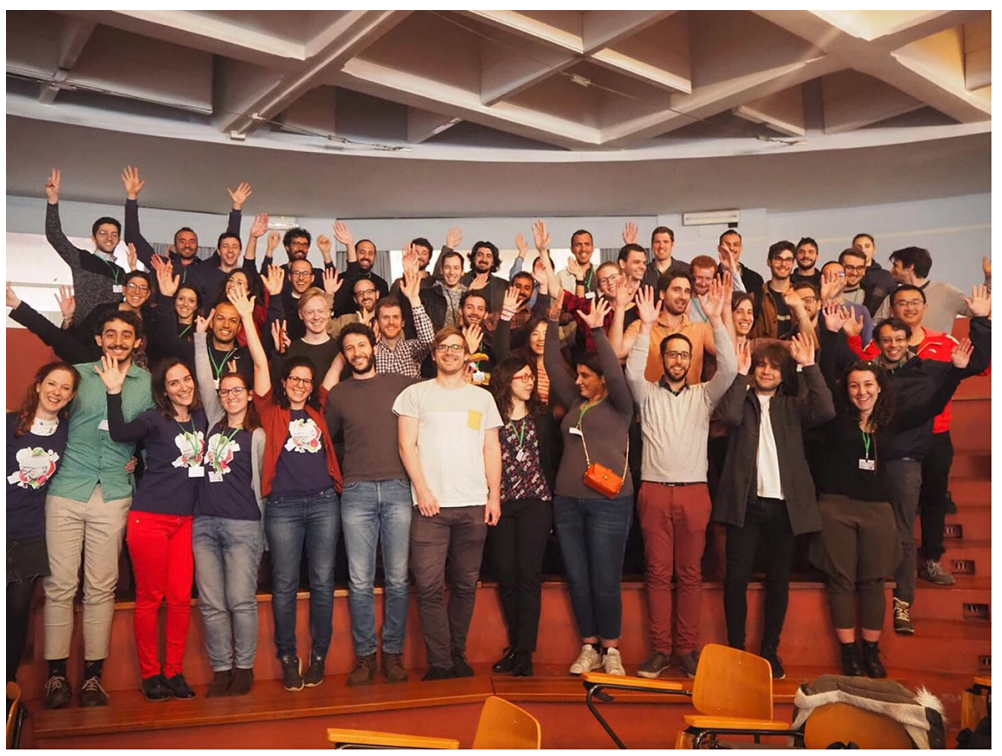

Fig. 2 3rd AIROYoung workshop and 1st AIROYoung Phd school

As we already mentioned, inclusion is a keyword in AIROYoung. Inclusion independently from funds, as we already discussed, but also inclusion for diversity in general. AIROYoung is particularly interested in gender equality. We are very proud of our all-female board and of the high number of women that actively contribute to the community (we had many initiatives and workshops run by female $\mathrm{PhDs}$ and PostDocs). We are actually facing now an unbalanced situation in the opposite sense, where most of the organizational tasks (board positions and event organizers) are female in AIROYoung, and we wish to balance this in the next future. The participation in our workshops is also quite balanced, with still a bit more men than women ( $40 \%$ vs $60 \%$ in the last workshop, for example). We hope that AIROYoung will provide female models for the new generations and show that STEM can be an embracing community for all.

AIROYoung also supports activities to attract to operations research. Indeed, operations research can be of great support in other disciplines and it can make the difference in the business companies, but it still not enough known and adopted. Recent initiatives in these directions have already started. For example, in the last edition of the AIROYoung workshop, we had an invited session dedicated to bridges between OR and data science, and we also had a session dedicated to divulgation and pitch talks. We are also very active on different social networks, trying to show applications of operations research also to people with a different background. Finally, we support activities to attract new generations to STEM and operations research. In particular, two of our members (Alice Raffaele and Alessandro Gobbi) are running different surveys and research activities at a European level to improve the knowledge of operations research among students and teachers in upper schools (Fig. 3). 


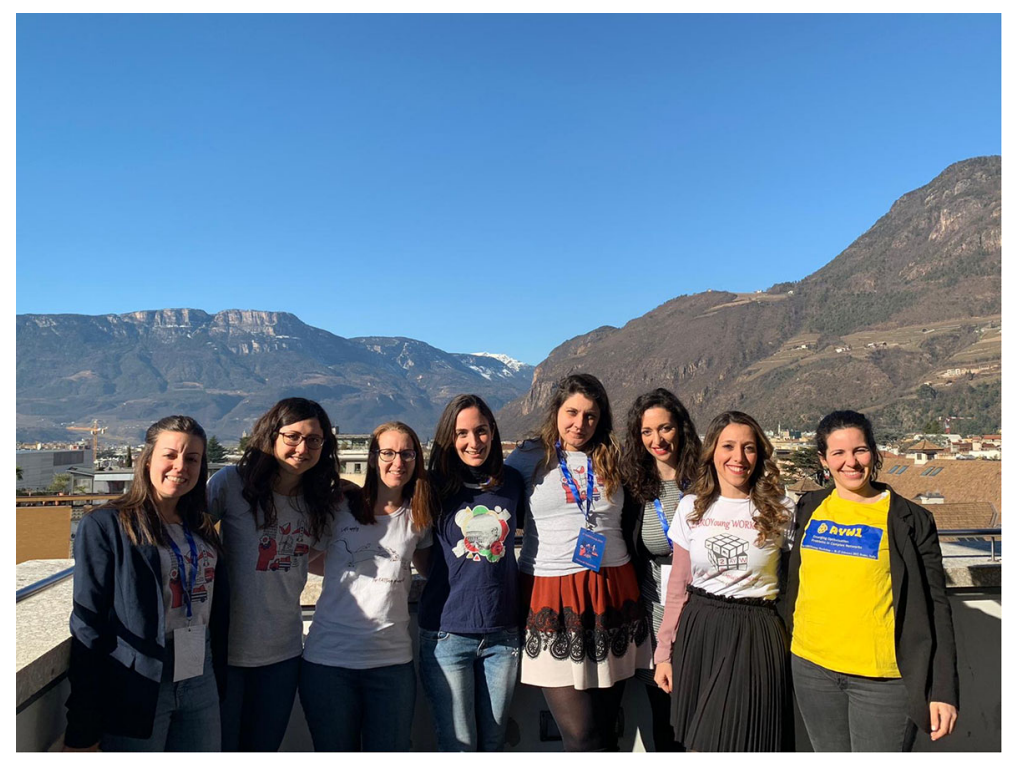

Fig. 3 Female organizers of our last workshops united in Bozen for the 4th AIROYoung workshop. Many active members of AIROYoung are female

\section{What We Learned from AIROYoung}

The AIROYoung experience has allowed us to create a community in which communication between young researchers and specialists in operations research is faster, very direct, and more informal than in the past. This made the development of soft skills easier among members and facilitated research ideas. Indeed, the friendly atmosphere that characterizes AIROYoung events represents an opportunity, especially for those who are at the beginning of their $\mathrm{PhD}$, to know the research topics of other colleagues, ask questions, gain confidence in the presentation of their work, and create a network. All this is obviously possible both thanks to the ever-growing participation of young $\mathrm{PhD}$ students and researchers in the AIROYoung events and community, but also thanks to the volunteering work and commitment put by the board and members who actively contribute to the organization and development of the chapter activities. The AIROYoung experiment can therefore continue by keeping alive the enthusiasm and spirit of initiative among members, but also by more interacting with the industry and similar communities, such as that of data science and statistic, and by promoting operations research among young students not only at the university level but also in lower schools. The AIROYoung community is always open to new ideas, proposals, and topics to discuss and new OR enthusiasts are always welcome!

Publisher's Note Springer Nature remains neutral with regard to jurisdictional claims in published maps and institutional affiliations. 